Gut, 1969, 10, 484-487

\title{
Polymeric collagen isolated from the human intestinal submucosa
}

\author{
F. S. STEVEN, D. S. JACKSON, J. D. SCHOFIELD, AND J. B. L. BARD \\ From the Department of Medical Biochemistry, Lapworth Laboratories, and the Biophysics Unit, \\ Rheumatism Research Centre, University of Manchester, Manchester
}

The intestinal submucosal layer has a special interest in view of its commercial use in sausage casings and also due to its importance in any study of normal and pathological changes in the human intestine. Although the submucosal layer has long been known to be a collageneous structure, no detailed report has been published for the isolation of highly pure submucosal collagen together with its chemical analysis and electron-microscopic appearance.

Earlier work from this laboratory has been concerned with the isolation and characterization of pure polymeric collagens from tendon and skin (Steven, 1964; Steven and Jackson, 1967), cornea (Freeman, Steven, and Jackson, 1968), intervertebral disc (Steven, Broady, and Jackson, 1968), and articular and intercostal cartilages (Steven, Broady, and Jackson, 1969). In each of these preparations it was necessary to pretreat the homogenized tissue with crude bacterial $\alpha$-amylase or ethylenediaminetetraacetate (EDTA) in order to release the collagen fibrils from the tissue matrix in which they were embedded.

In the present study the polymeric collagen fibrils of the intestinal submucosa could be released by treatment with dilute acetic acid alone. The amino-acid composition of these polymeric collagen fibrils indicated that they consisted of at least $95 \%$ pure collagen. The purity of the polymeric collagen was further improved after treating the tissue beforehand with crude bacterial $\alpha$-amylase or with EDTA.

\section{MATERIALS AND METHODS}

PREPARATION OF TISSUE Human intestines were removed as soon as possible at necropsy from subjects with no known intestinal abnormality. The tissues were carefully washed with water and the submucosal layer was scraped clean of the mucosa and muscularis layers. Segments of the submucosal layer from both the small and large intestine were removed and separately frozen in liquid nitrogen. The tissues were crushed in a stainless steel hammer mill (Steven, 1967; Walser and Bodenloss, 1954) and exhaustively washed in $0.5 \mathrm{M} \mathrm{NaCl}$ by centrifugation until the supernatant was clear and contained no solubilized protein.

ACETIC ACID EXTRACTION Part of the homogenized tissue was suspended in $51.0 .2 \mathrm{M}$ acetic acid and allowed to equilibrate to $p \mathrm{H} 3.2$ to 3.5 over a period of one hour. The tissue was then homogenized in an Utraturrax homogenizer for 10 seconds, followed by constant stirring at $4^{\circ}$ for 18 hours. The supernatant fluid containing polymeric collagen fibrils was removed by centrifugation at $300 \mathrm{~g}$ for $20 \mathrm{~min}$ at $4^{\circ} \mathrm{C}$ and the fibrils were collected by raising the $p \mathrm{H}$ to 5 to 6 with $\mathrm{M} . \mathrm{NaOH}$ and stirring with a spatula (Steven, 1964; Steven and Jackson, 1967). Polymeric collagen fibrils were purified from noncollageneous proteins by redispersing in acetic acid four times followed by precipitation of the fibrils by the addition of saturated $\mathrm{NaCl}$ to give a final concentration of 3 to $4 \% \mathrm{w} / \mathrm{v}$.

GELATIN FORMATION Acetic-acid-extracted polymeric collagen fibrils were autoclaved at $p \mathrm{H} 7.0$ for six $\mathrm{hr}$ at $15 \mathrm{lb} /$ in. $^{2}$; the insoluble residue contained $94 \%$ of the initial collagen and the soluble fraction $6 \%$ respectively. The soluble fraction was purified as a gelatin after precipitation of non-collagenous impurities with $5 \%$ trichloracetic acid and precipitation of the gelatin with 10 volumes of acetone (Jackson, 1957). The insoluble residue was autoclaved in water for a further six hr at $30 \mathrm{lb} / \mathrm{in}^{2}$ but failed to yield any further soluble gelatin fraction.

CRUDE $\alpha$-AMYLASE TREATMENT Part of the tissue homogenate was treated with crude $\alpha$-amylase, $1 \% \mathrm{w} / \mathrm{w}$, as previously described for tendon and skin (Steven, 1964; Steven and Jackson, 1967), and the polymeric collagen fibrils were collected and purified as above, all steps being carried out at $4^{\circ} \mathrm{C}$.

EDTA TREATMENT Part of the tissue homogenate was treated with $4 \% \mathrm{w} / \mathrm{v}$ EDTA $p H 7 \cdot 5$ (Steven, 1967) and the polymeric collagen fibrils were isolated and purified as above.

AMINO ACID ANALYSIS The collagen and gelatin preparations were subjected to 24 hr hydrolysis under nitrogen in $6 \mathrm{~N} \mathrm{HCl}$ and amino acid analysis was carried out on the 
21-hour Technicon sodium buffer system as previously described (Steven, 1967; Steven and Jackson, 1967).

ELECTRON MICROSCOPY Samples of submucosal polymeric collagen fibrils dispersed in $0 \cdot 1 \mathrm{M}$ acetic acid were placed on carbon-collodion-coated grids and negatively stained with $1 \% \mathrm{w} / \mathrm{v}$ sodium phosphotungstate $p \mathrm{H} \mathrm{7.0.}$ The grids were examined in the AEI-EM-6B electronmicroscope.

\section{RESULTS AND DISCUSSION}

YIELD OF POLYMERIC COLLAGEN Virtually all the collagen of the submucosal tissue was capable of dispersion into $0.1 \mathrm{M}$ acetic acid as polymeric collagen fibrils, and less than $10 \%$ remained in the insoluble residue after two extractions with acetic acid. The yield was not affected by pretreatment of the tissue with either crude $\alpha$-amylase or by EDTA.

The ease with which dilute acetic acid disperses the polymeric collagen fibrils of the intestinal submucosa is in marked contrast to the difficulties encountered with other connective tissues. Skin and tendon require a pretreatment with crude bacterial $\alpha$-amylase (Steven, 1964; Steven and Jackson, 1967) or EDTA (Steven, 1967) before the polymeric collagen fibrils can be dispersed in acetic acid. These pretreatments do not release pure polymeric collagen from human cartilage unless it is further treated with a proteolytic enzyme such as trypsin (Steven et al, 1968 and 1969). Bone decalcified with EDTA and treated with crude $\alpha$-amylase followed by trypsin cannot be dispersed in acetic acid to yield pure polymeric collagen fibrils. It is suggested that the submucosal polymeric collagen fibrils have very little interaction with other non-collageneous components of this tissue and that they represent the least complex organization of polymeric collagen fibrils at this tissue level so far studied.

DEGREE OF POLYMERIZATION OF POLYMERIC COLLAGEN Prolonged autoclaving of collagen is known to produce peptide bond cleavage with the formation of a soluble polydisperse polypeptide fraction usually referred to as gelatin. Human skin and tendon polymeric collagen is completely solubilized after one hour's autoclaving. The marked insolubility of submucosal polymeric collagen after 12 hours' autoclaving indicates a very high degree of intermolecular cross-linking or polymerization within the polymeric collagen fibrils. These crosslinkages are stable and prevent the solubilization of polypeptide fragments resulting from peptide bond cleavage during autoclaving.

AMINO ACID COMPOSITION OF POLYMERIC COLLAGEN The analyses presented in Table I indicate that both the crude $\alpha$-amylase and EDTA-prepared polymeric collagen fibrils were highly purified. The polymeric collagen fibrils extracted with acetic acid alone contained some 6 to $7 \%$ impurity calculated on the content of hydroxyproline and proline as well as glycine residues. This impurity could be removed from the polymeric collagen by autoclaving and

TABLE I

AMINO ACID COMPOSITIONS OF POLYMERIC COLLAGENS AND DERIVED GELATIN OBTAINED FROM HUMAN INTESTINAL SUBMUCOSA ${ }^{1}$

\begin{tabular}{|c|c|c|c|c|}
\hline \multirow[t]{2}{*}{ Preparation } & \multirow{2}{*}{$\begin{array}{l}\text { Acetic-acid Extracted } \\
\text { Polymeric Collagen }\end{array}$} & \multirow{2}{*}{$\begin{array}{l}\text { Derived Gelatin } \\
(\text { Gel-1) }\end{array}$} & \multicolumn{2}{|c|}{ Polymeric Collagen } \\
\hline & & & a-Amylase & $E D T A$ \\
\hline Hydroxyproline & $81 \cdot 3$ & $95 \cdot 1$ & $97 \cdot 1$ & $95 \cdot 4$ \\
\hline Aspartic acid & $54 \cdot 2$ & $54 \cdot 1$ & $51 \cdot 4$ & $52 \cdot 4$ \\
\hline Threonine & $19 \cdot 2$ & $16 \cdot 3$ & $18 \cdot 4$ & $16 \cdot 4$ \\
\hline Serine & $32 \cdot 3$ & $36 \cdot 1$ & $35 \cdot 8$ & 39.0 \\
\hline Glutamic acid & $80 \cdot 2$ & $74 \cdot 2$ & $77 \cdot 4$ & $77 \cdot 8$ \\
\hline Proline & $105 \cdot 3$ & $115 \cdot 7$ & $110 \cdot 1$ & 112.6 \\
\hline Glycine & $313 \cdot 7$ & $339 \cdot 7$ & 315.9 & 315.4 \\
\hline Alanine & $117 \cdot 2$ & $105 \cdot 5$ & $111 \cdot 1$ & $118 \cdot 4$ \\
\hline Valine & $34 \cdot 4$ & $23 \cdot 4$ & $28 \cdot 1$ & $27 \cdot 2$ \\
\hline Methionine & 1.9 & Trace & $2 \cdot 1$ & Trace \\
\hline Isoleucine & $16 \cdot 0$ & $12 \cdot 1$ & $14 \cdot 4$ & $12 \cdot 0$ \\
\hline Leucine & $31 \cdot 5$ & 25.0 & $27 \cdot 1$ & $26 \cdot 7$ \\
\hline Tyrosine & $4 \cdot 5$ & $2 \cdot 5$ & $4 \cdot 2$ & 2.7 \\
\hline Phenylalanine & $14 \cdot 4$ & $11 \cdot 1$ & $14 \cdot 3$ & $12 \cdot 8$ \\
\hline Hydroxylysine & $5 \cdot 3$ & $7 \cdot 5$ & $7 \cdot 2$ & $5 \cdot 7$ \\
\hline Ornithine & $2 \cdot 7$ & $2 \cdot 0$ & $1 \cdot 1$ & Trace \\
\hline Lysine & $30 \cdot 2$ & $28 \cdot 4$ & $26 \cdot 8$ & $29 \cdot 3$ \\
\hline Histidine & $5 \cdot 0$ & $4 \cdot 7$ & $7 \cdot 2$ & 6.0 \\
\hline Arginine & $49 \cdot 6$ & $46 \cdot 6$ & $50 \cdot 2$ & $50 \cdot 2$ \\
\hline Total & $999 \cdot 9$ & $1,000 \cdot 0$ & 999.9 & $1,000 \cdot 0$ \\
\hline
\end{tabular}

${ }^{1}$ Results have been expressed as residues per 1,000 total residues after allowing for hydrolytic losses (Steven and Jackson, 1967). 


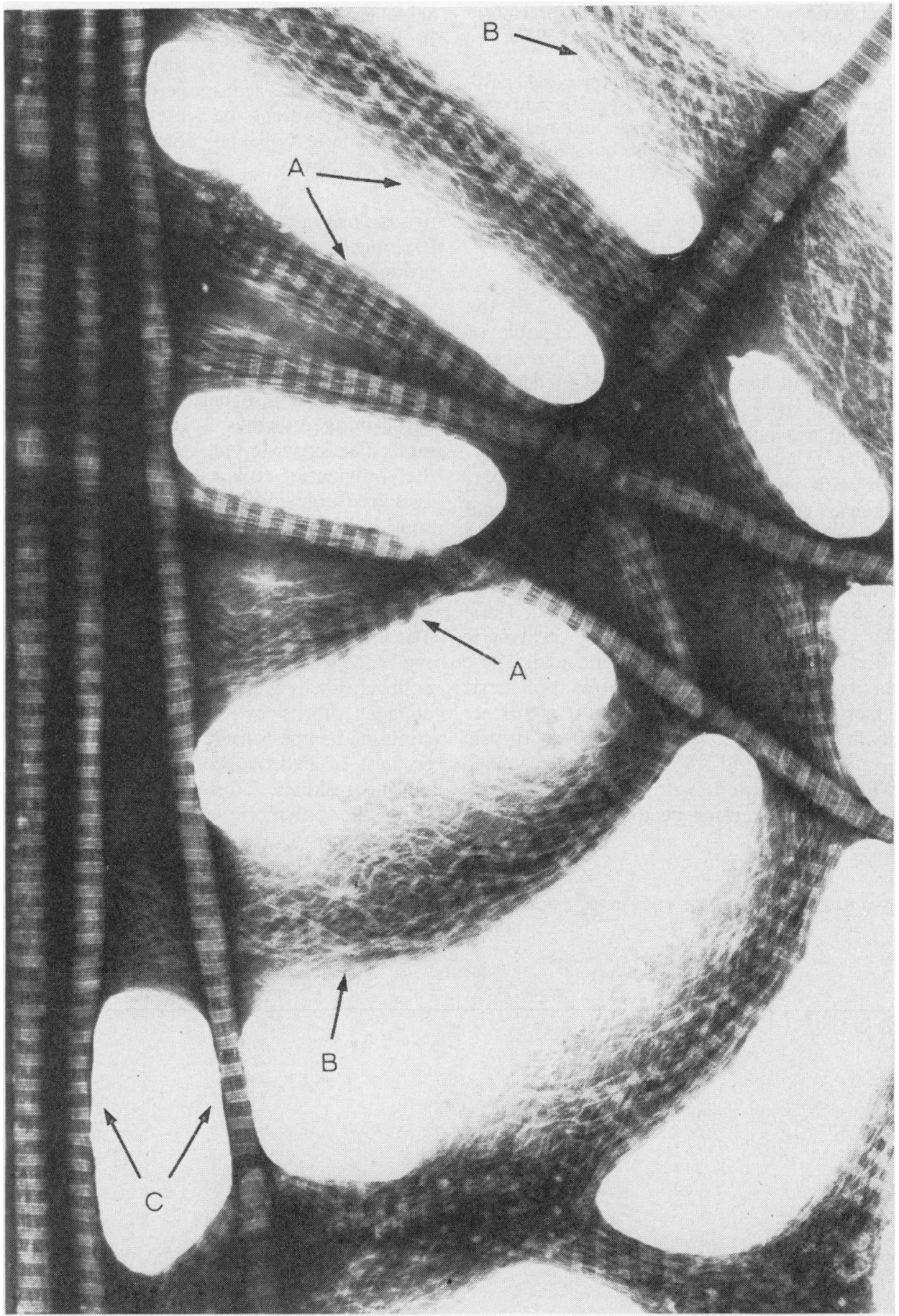

FIG. 1. Intestinal submucosal polymeric collagen fibrils negatively contrasted with sodium phosphotungstate $(\mathrm{pH} 7 \cdot 0) \times 50,000$, showing fibrils swollen but still maintaining 640 A periodicity (A) and swollen stocking-like structure (B) in addition to unswollen native type collagen fibrils (C). 
purifying the derived gelatin $(6 \%$ of the total polymeric collagen) by trichloracetic acid and acetone precipitation (see figures for gel-1, Table I).

The hydroxylysine content of intestinal submucosal polymeric collagen is lower than tendon and cartilage polymeric collagen (Steven et al, 1969). The sum of lysine plus hydroxylysine polymeric collagen obtained from these tissues is approximately constant as would be expected from the fact that hydroxylysine is derived from lysine in protocollagen (Kivirikko and Prockop, 1967; Prockop and Kivirikko, 1967).

ELECTRON MICROSCOPIC EXAMINATION OF POLYMERIC COLLAGEN Examination of submucosal polymeric collagen fibrils dispersed in $0 \cdot 1 \mathrm{M}$ acetic acid demonstrated the typical $640 \AA$ striated fibrils (A, Fig. 1) as well as fibrils which were partially unravelled (B, Fig. 1). The protofibrils which make up the fibril can be seen to be organized in the form of a 'stocking' type of structure, with some evidence of superhelical organization. Stirtz (1967) has also published evidence suggesting a superhelical organization of protofibrils within collagen fibrils. The swollen fibrils (B in Fig. 1) appear unable to be completely unravelled. This suggests that a limited number of interprotofibrillar bonds may be present and that these place a restriction on the dispersal of the protofibrils in dilute acetic acid.

It may be concluded that the human submucosa contains polymeric collagen fibrils which are very loosely held in the interfibrillar matrix and that dilute acetic acid readily extracts at least $90 \%$ of the polymeric collagen in the form of dispersed fibrils. The polymeric collagen fibrils are composed of a large number of superhelically organized protofibrils, whilst at the molecular level there must be a high degree of intermolecular cross-linking which is stable to autoclaving in marked contrast to other polymeric collagens so far studied.
SUMMARY

Treatment of human intestinal submucosa with dilute acetic acid allowed the dispersal of polymeric collagen fibrils which were purified by salt precipitation. These fibrils were $97 \%$ pure collagen. Treating the tissue beforehand with crude bacterial $\alpha$-amylase or EDTA resulted in the dispersion of pure polymeric collagen fibrils. The amino acid composition and the electron microscopic appearance of intestinal submucosa polymeric collagen fibrils are reported.

We wish to thank Dr A. Jones for provision of the intestines and Miss $\mathrm{K}$. Broady for her excellent work on the Technicon AutoAnalyzer system.

J.D.S. and J.B.L.B. wish to thank the S.R.C. for research studentships held during the course of this study.

\section{REFERENCES}

Freeman, I. L., Steven, F. S., and Jackson, D S. (1968). Isolation and amino acid composition of bovine corneal polymeric collagens. Biochim. biophys. Acta (Amst.), 154, 252-254.

Jackson, D. S. (1957). Connective tissue growth stimulated by carrageenin. 1. The formation and removal of collagen. Biochem. J., 65, 277-284.

Kivirikko, K. I., and Prockop, D. J. (1967). Enzymatic hydroxylation of proline and lysine in protocollagen. Proc. nat. Acad. Sci. (Wash.), 57, 782-789.

Prockop, D. J., and Kivirikko, K. I. (1967). Relationship of hydroxyproline excretion in urine to collagen metabolism. Ann. intern. Med., 66, 1243-1266.

Steven, F. S. (1964). The Nishihara technique for the solubilization of collagen. Ann. rheum. Dis., 23, 300-301.

(1967). The effect of chelating agents on collagen interfibrillar matrix interactions in connective tissue. Biochim. biophys. Acta (Amst.), 140, 522-528.

—, Broady, K., and Jackson, D. S. (1968'. Ibid., 160, 435-446.

,,$-- \ldots$ (1969). Ibid., 175, 225-227.

- , and Jackson, D. S. (1967). Purification and amino acid composition of monomeric and polymeric collagens. Biochem. J., 104, 334-536.

Stirtz, T. (1967). Leder, 18, 193-204.

Walser, M., and Bodenlos, L. J. (1954). Composition of skin as compared with muscle. Amer. J. Physiol., 178, 91-96. 